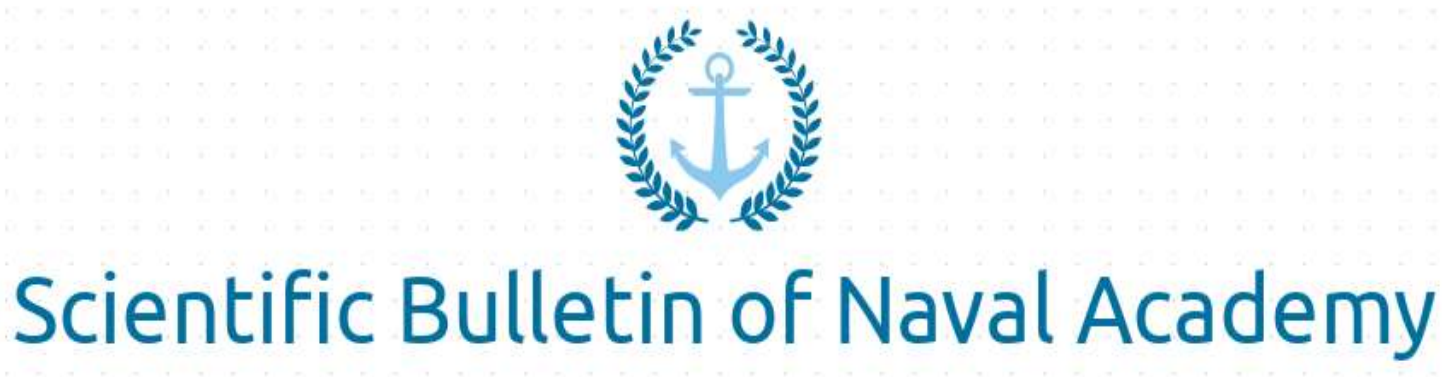

SBNA PAPER • OPEN ACCESS

Matlab Simulink simulation of naval electric propulsion using synchronous motor fed from cycloconverter drive

To cite this article: V Mocanu, Scientific Bulletin of Naval Academy, Vol. XXIII 2020, pg.231-238.

Available online at www.anmb.ro

ISSN: 2392-8956; ISSN-L: 1454-864X

doi: $10.21279 / 1454-864 X-20-12-032$

SBNA@ 2020. This work is licensed under the CC BY-NC-SA 4.0 License 


\title{
Matlab Simulink simulation of naval electric propulsion using synchronous motor fed from cycloconverter drive
}

\author{
V Mocanu \\ University Assistant PhD Candidate, Naval Academy "Mircea cel Bătrân”, Constanța, RO \\ E-mail: m.vladmocanu@gmail.com
}

\begin{abstract}
The content of the paper presents the virtual construction of an electric propulsion system from the source to synchronous motor with variable speed which drives the propeller. The variable speed of the propeller is obtained by changing the frequency of the supply voltage produced by the cycloconverters (12 pulses). Electric propulsion system simulation with cycloconverter is made in Matlab Simulink, which highlights the characteristics of the synchronous motor used in naval propulsion.
\end{abstract}

Keywords: electric propulsion, synchronous motor, cycloconverters

\section{Introduction}

The evolution of electricity in marine ships first began with lighting, moving on to hybrid propulsion systems with steam turbines and diesel engines, and now reaching full-electric ships by using batteries.

Electrical installations are present on all ships, from the supply of communication and navigation equipment, alarms and monitoring systems, engine operation, pumps, fans, winches, to high-power installations for electric propulsion.

Currently, electric propulsion is applied especially for the following types of ships: cruise ships, ferries, drilling ships, tugboats, transfer ships, icebreakers, supply ships, warships.

The ship propulsion system plays an important role in its performance, so the choice of propulsion type must meet the operational needs of the ship. [1]

For naval electric propulsion system implementation, certain parameters must be met, as follows:

- rapid adaptation of the system to ship propulsion demand variations, caused by wind, waves, currents, sudden changes of direction;

- restricted space for the propulsion system;

- operational safety and facilitation of access for control and maintenance during operation;

- the general cost of transport, being closely related to the specific fuel consumption, the number of crew (operators) and its preparation;

- the cost related to the initial investment and maintenance.

Classic propulsion systems including the main propulsion machine, shaft transmission, and propeller no longer satisfy the modern needs in terms of maneuverability, comfort, emissions, etc.

Pod and Azipod propulsion system type represents an alternative of modern propulsion options. The speed variation of pod or azipod propeller is accomplished by supplying the synchronous motor drive propeller from a cycloconverter, by varying the supply frequency. [2] 
2. Mathematical modeling of the propeller-synchronous motor-converter assembly, used for ship propulsion

\section{Propeller [3]}

For a fixed-pitch propeller, the relationship between propulsion, torque, and power can be determined as follows:

where: $\quad T_{p}$ - propeller thrust $[N]$,

$$
\begin{aligned}
& T_{p}=\rho D^{4} K_{T} n|n| \\
& Q_{p}=\rho D^{5} K_{Q} n|n| \\
& P_{p}=\frac{2 \pi}{60} n Q_{p}
\end{aligned}
$$

$n$ - propeller shaft speed $[r / \mathrm{min}]$,

$Q_{p}$ - propeller torque $[\mathrm{Nm}]$,

$P_{p}$ - propeller power $[W]$.

$\rho$ - water density $\left[\mathrm{kg} / \mathrm{m}^{3}\right]$,

$D$ - propeller diameter $[m]$,

$K_{t}$ - propulsion coefficient,

$K_{Q}$ - torque coefficient.

Rearranging the formulas (1) and (3), results:

$$
\begin{aligned}
& n=\operatorname{sign}\left(\frac{T}{\rho D^{4} K_{T}}\right) \sqrt{\left|\frac{T}{\rho D^{4} K_{T}}\right|} \\
& Q_{p}=\frac{D K_{Q}}{K_{T}} T \\
& P_{p}=\operatorname{sign}\left(\frac{T}{\rho D^{4} K_{T}}\right) \sqrt{\left|\frac{T}{\rho D^{4} K_{T}}\right|}
\end{aligned}
$$

Formula (6) can be written as:

$$
P_{p}=k \cdot \operatorname{sign}(T) T \sqrt{|T|}
$$

where:

\section{Synchronous propulsion motor [3]}

$$
k=1 / \sqrt{\left(\rho D^{4} K_{T}\right)^{3}}
$$

The propeller model inputs are: $n_{p}$ - propeller shaft speed, $Q_{p}$ - mechanical torque of propeller shaft, $P_{p}$ - propeller shaft power. Synchronous motor losses are simplified in four terms, electric rotor and stator losses, core and friction losses.

$$
P_{\text {synchronous motor losses }}=r_{f} i_{f}^{2}+r_{a} i_{a}^{2}+\frac{e_{a g}^{2}}{r_{m s}}+k_{f_{1}} n_{p}
$$

where: $r_{f} i_{f}^{2}$ - field and current winding losses,

$r_{a} i_{a}^{2}$ - armature and current winding losses,

$r_{m s}$ - equivalent of core loss resistance,

$e_{a g}^{2}$ - air gap voltage,

$k_{f_{1}}$ - friction constant,

therefore:

$n_{p}$ - propeller shaft speed.

$$
\begin{array}{r}
i_{a}=k_{1} Q_{p} \rightarrow k_{1}=\frac{i_{a N}}{Q_{p N}} \\
e_{a g}=k_{2} n_{p} \rightarrow k_{2}=\frac{e_{a g N}}{n_{p N}}
\end{array}
$$


where: $i_{f}$ - field current, for simplicity it is supposed to be:

$$
i_{f}=k_{3}+k_{4} i_{a}=k_{3}+k_{4} k_{1} Q_{p}
$$

where: $k_{3}$ - excitation at no-load speed și $k_{4}$ - approximate excitation due to load variation.

These constants should be chosen according to the motor characteristic data. Subscriber N indicates the nominal values. This efficiency becomes:

$$
\begin{aligned}
& P_{\text {synchronous motor losses }}=r_{f} i_{f}^{2}+k_{5} Q_{p}^{2}+k_{6} n_{p}^{2}+f_{r} n_{p} \\
& P_{m}=P_{p}+P_{\text {synchronous motor losses }} \\
& I_{m}=k_{1} Q_{p}
\end{aligned}
$$

where:

$$
k_{5}=k_{1}^{2} r_{a}, k_{6}=k_{2}^{2} / r_{m s}
$$

\section{Cycloconverter [3]}

It is assumed that the conduction losses are dominant and the appropriate loss model for the characteristic curve is given by:

$$
P_{\text {cycloconverter losses }}=P_{0}+k_{15} I_{m}+k_{16} I_{m}^{2}
$$

where: $I_{m}$ - motor current is given by equation (15),

$P_{0}$ - represents possible reverse recovery losses, cooling losses, etc.,

$k_{15}$ și $k_{16}$ - constants that represent conduction losses.

The cycloconverter is usually combined with a synchronous motor for propulsion and the power factor of the grid depends largely on the firing angle of the cycloconverter.

where: $P F$ - power factor,

$$
\begin{aligned}
& P F=P F_{\text {max }}, P_{m}>P_{P F_{\text {max }}} \\
& P F=P F_{\text {min }}, P_{m}<P_{P F_{\text {min }}} \\
& \quad P F=P_{P F_{\text {min }}}+\frac{P F_{\text {max }}-P F_{\text {min }}}{P_{P F_{\text {max }}}-P_{P F_{\text {min }}}}\left(P_{m}-P_{P F_{\text {min }}}\right) \\
& P_{P F_{\text {min }}<P_{m}<P_{P F_{\text {min }}}}
\end{aligned}
$$

$P_{P F}$ - load power at a certain $\mathrm{PF}$,

$P_{m}$ - load power.

\section{Simulation}

Ship electric propulsion is reproduced in the Matlab/Simulink to observe and interpret the mechanical and electrical parameters, having a constant load propeller driven by a synchronous motor. The advantage of synchronous motors will be highlighted, that of keeping their torque constant at variable supply frequencies.

Figure 1 shows the entire supply system of the synchronous motor from a cycloconverter, but also displays cycloconverter control, measurement of mechanical/electrical values, and adjustment of parameters. 


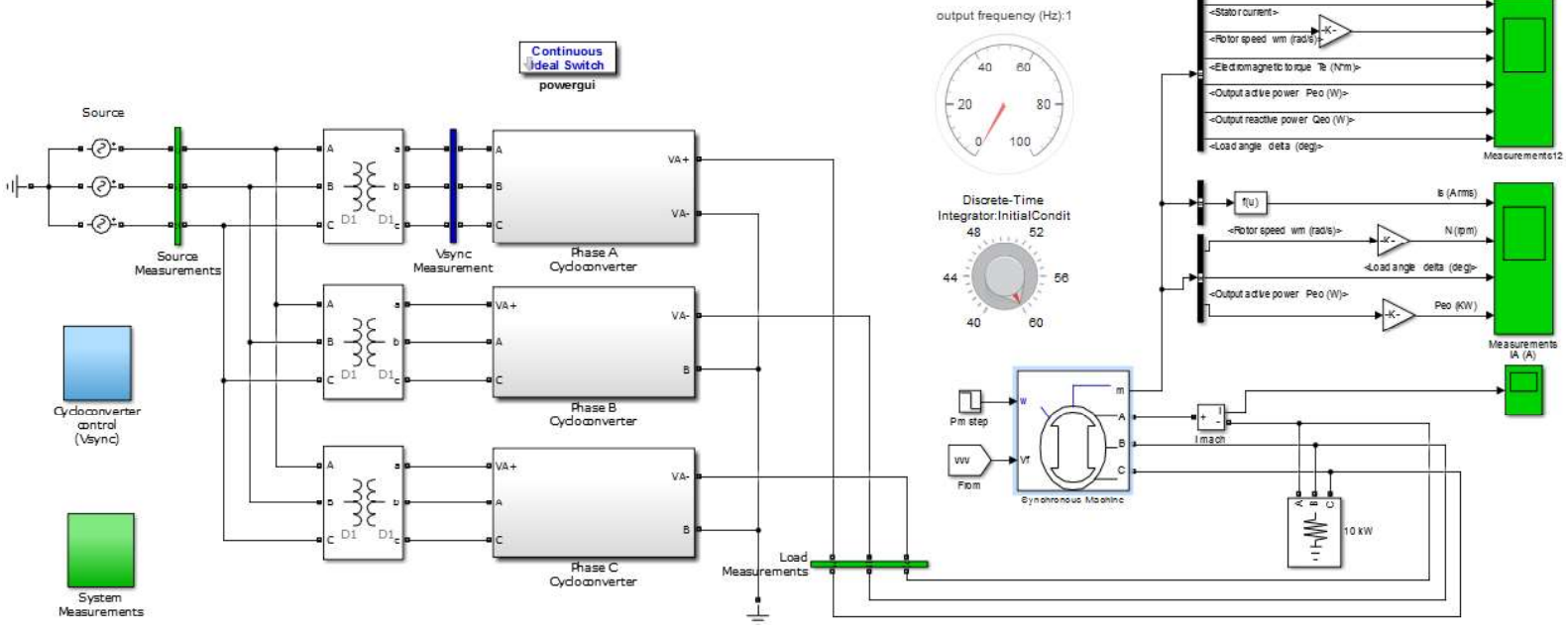

Figure 1. Diagram of synchronous motor fed from cycloconverter drive

The simulation purpose is to present as accurately as possible the operation of electric propulsion onboard a passenger ship. Measurements were made for three different synchronous motor supply frequencies: $50 \mathrm{~Hz}, 60 \mathrm{~Hz}, 70 \mathrm{~Hz}$.

The propeller load driven by synchronous motor remains constant throughout the simulation; the constant load is the equivalent of a calm sea with $0-1$ degree, which produces almost insignificant variations of the electric motor shaft load.

Three different starts of synchronous motor powered from a cycloconverter at the three frequencies were performed. The graphs of monitored values are presented below:

\section{Electrical parameters}

Measurements of electrical parameters were performed at all three output cycloconverter frequencies. The voltage and frequency of cycloconverter power supply were kept constant, as well as the electric propulsion motor shaft load.

In figures 2,3,4 are represented the graphs obtained for electrical parameters, at three supply frequencies of synchronous motor, where: (a) Source voltages, b) Source currents, c) Comparison between the load voltage waveform and the reference voltage, d) Load voltages, e) Load currents:

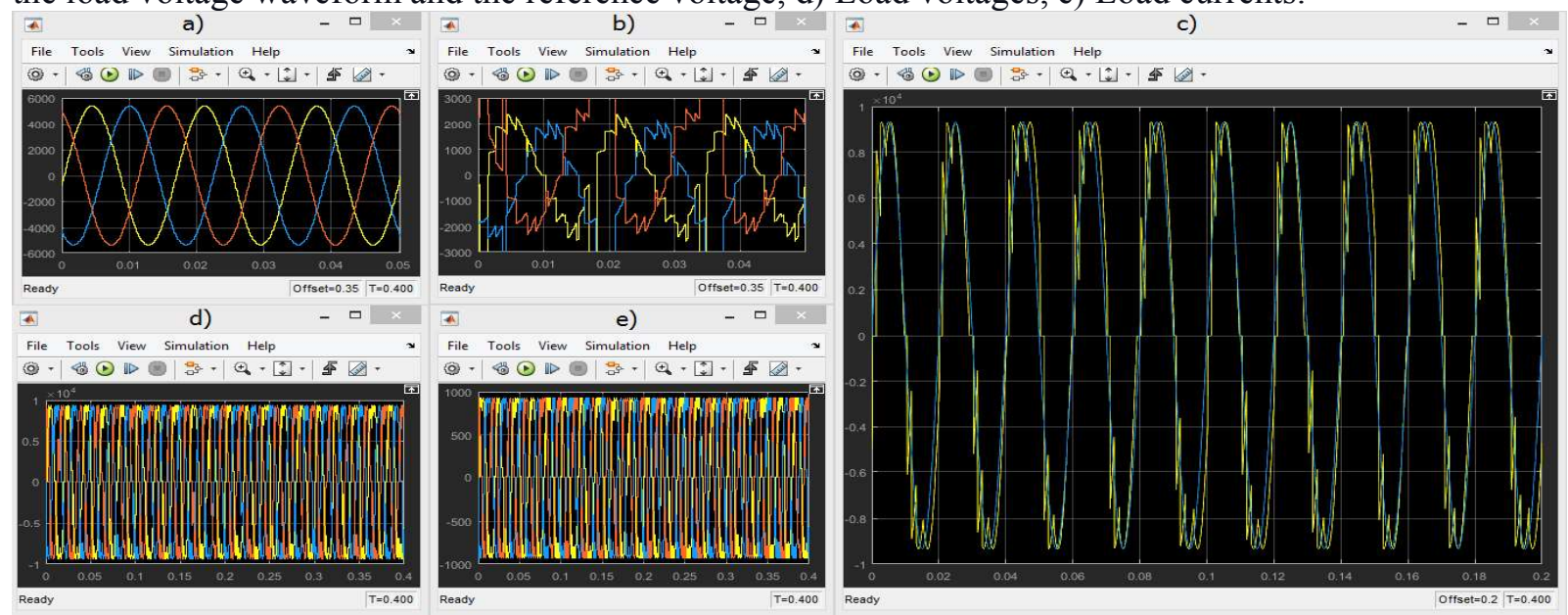

Figure 2. Parameters obtained at $50 \mathrm{~Hz}$ cycloconverter output frequency 


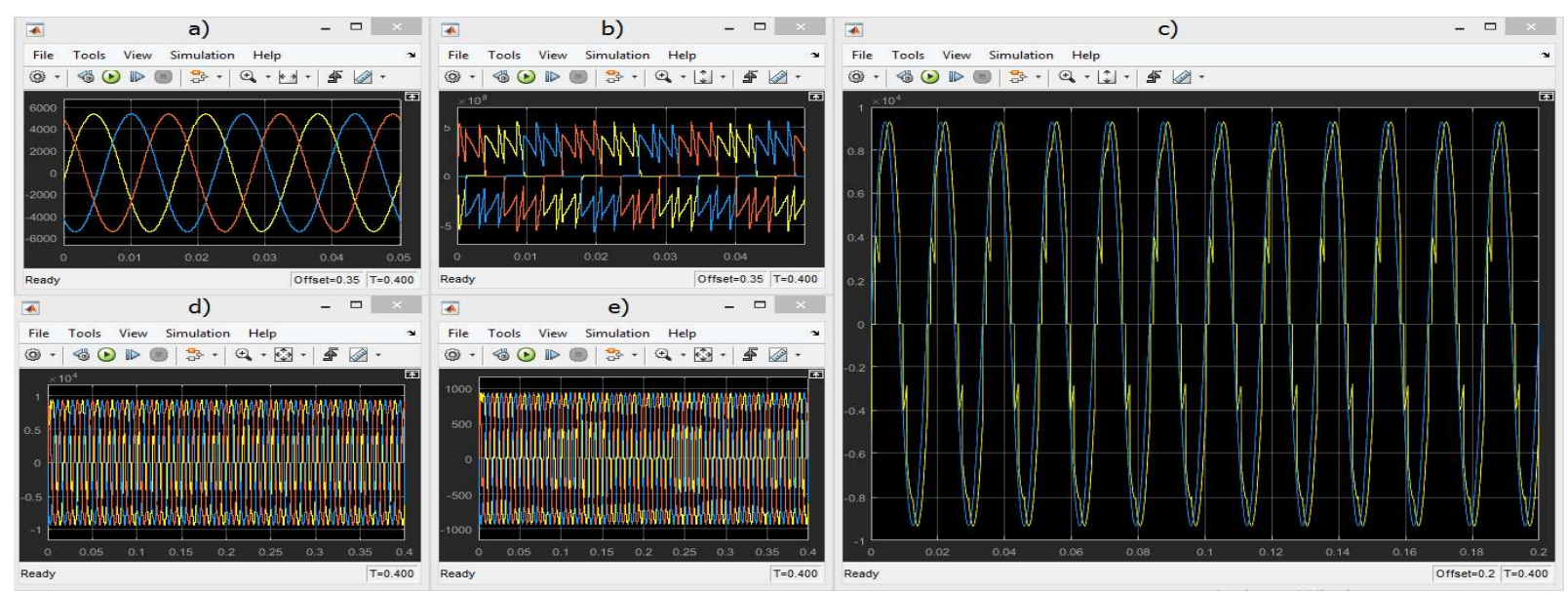

Figure 3. Parameters obtained at $60 \mathrm{~Hz}$ cycloconverter output frequency

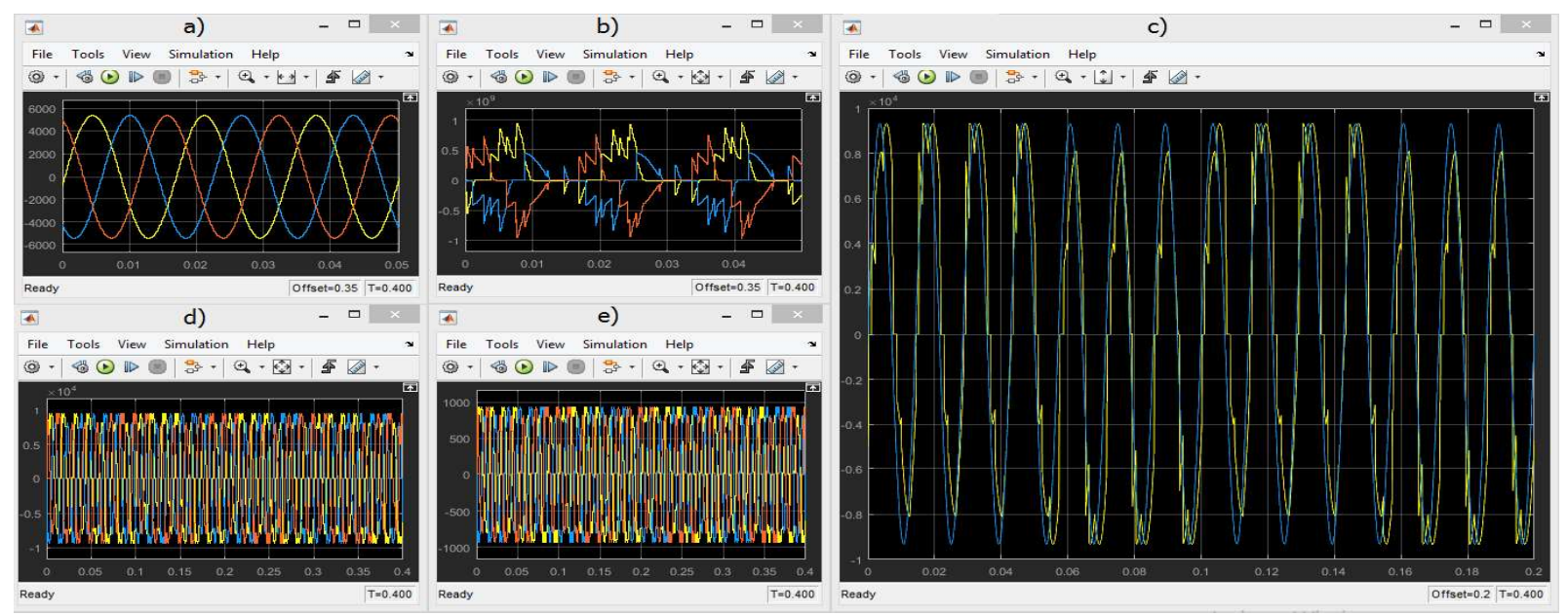

Figure 4. Parameters obtained at $70 \mathrm{~Hz}$ cycloconverter output frequency

\section{Mechanical parameters}

In parallel with electrical parameters monitoring, were made measurements on three-phase synchronous propulsion motor mechanical parameters, at all three supply frequencies from cycloconverter, keeping a constant load on propulsion motor shaft.

Further, are presented the parameters: a) Starting speed, b) Starting torque for supply frequencies of the three-phase synchronous propulsion motor in figures 5,6,7. 

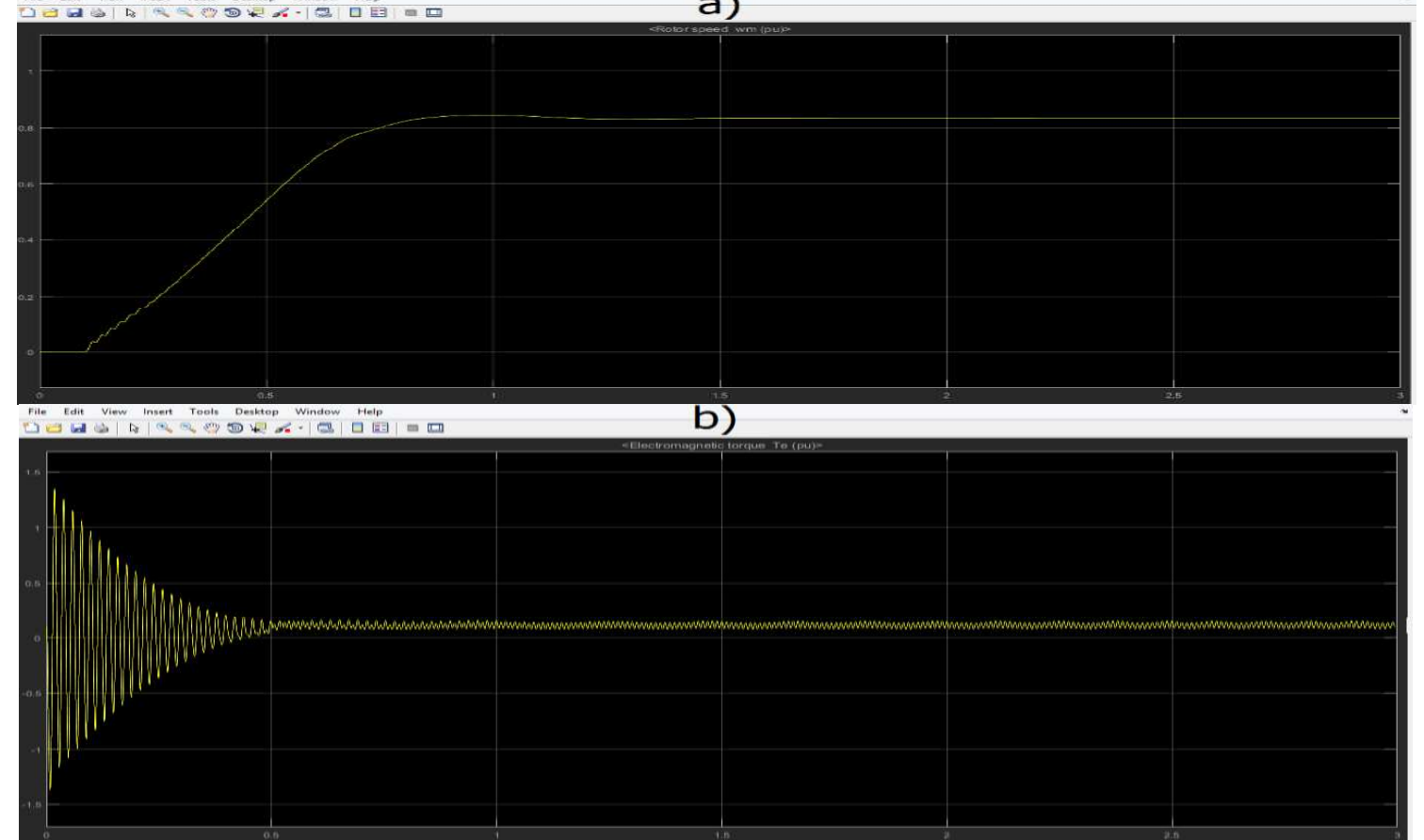

Figure 5. Parameters obtained at $50 \mathrm{~Hz}$ three-phase synchronous motor supply frequency

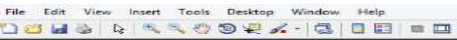

a)

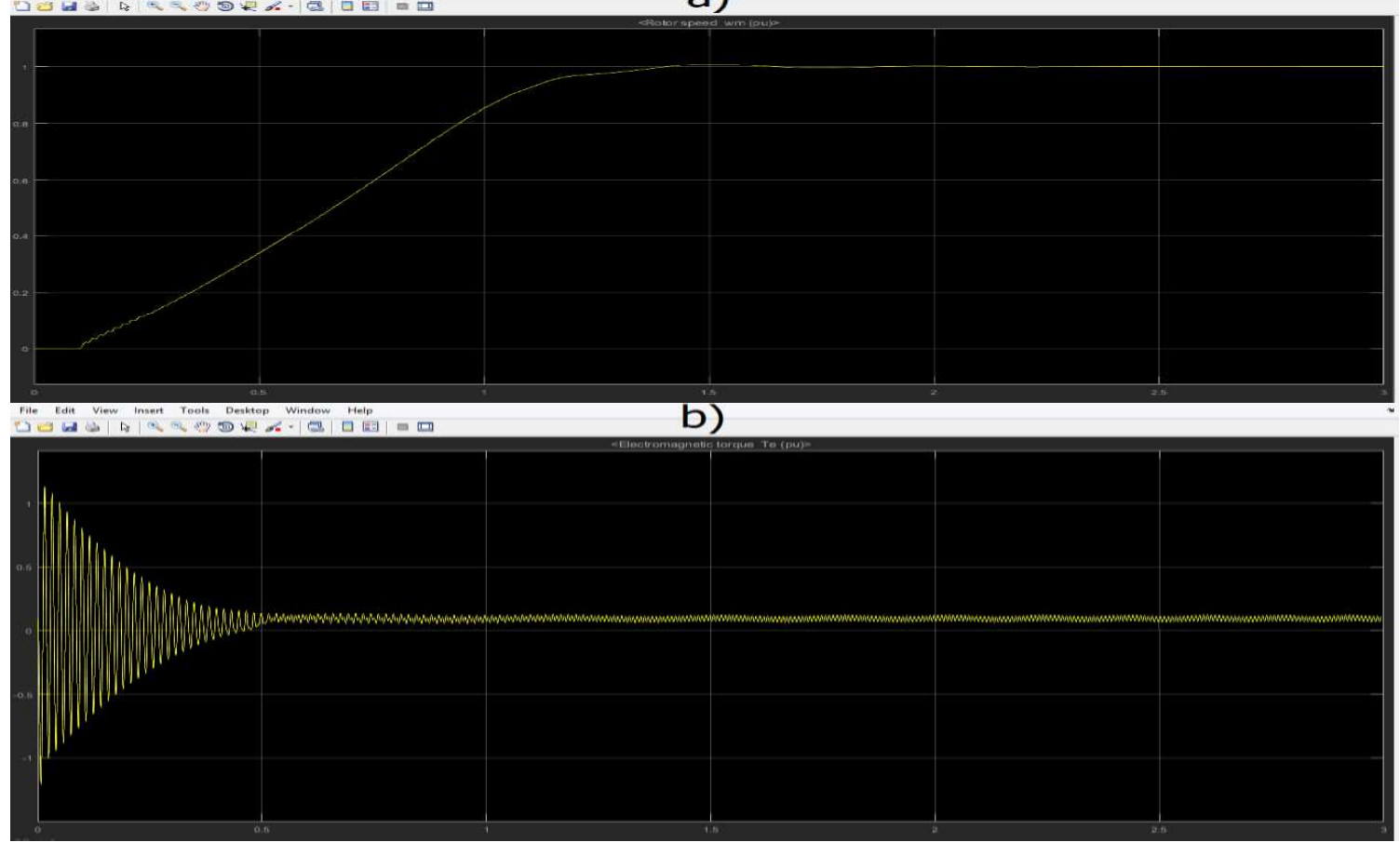

Figure 6. Parameters obtained at $60 \mathrm{~Hz}$ three-phase synchronous motor supply frequency 

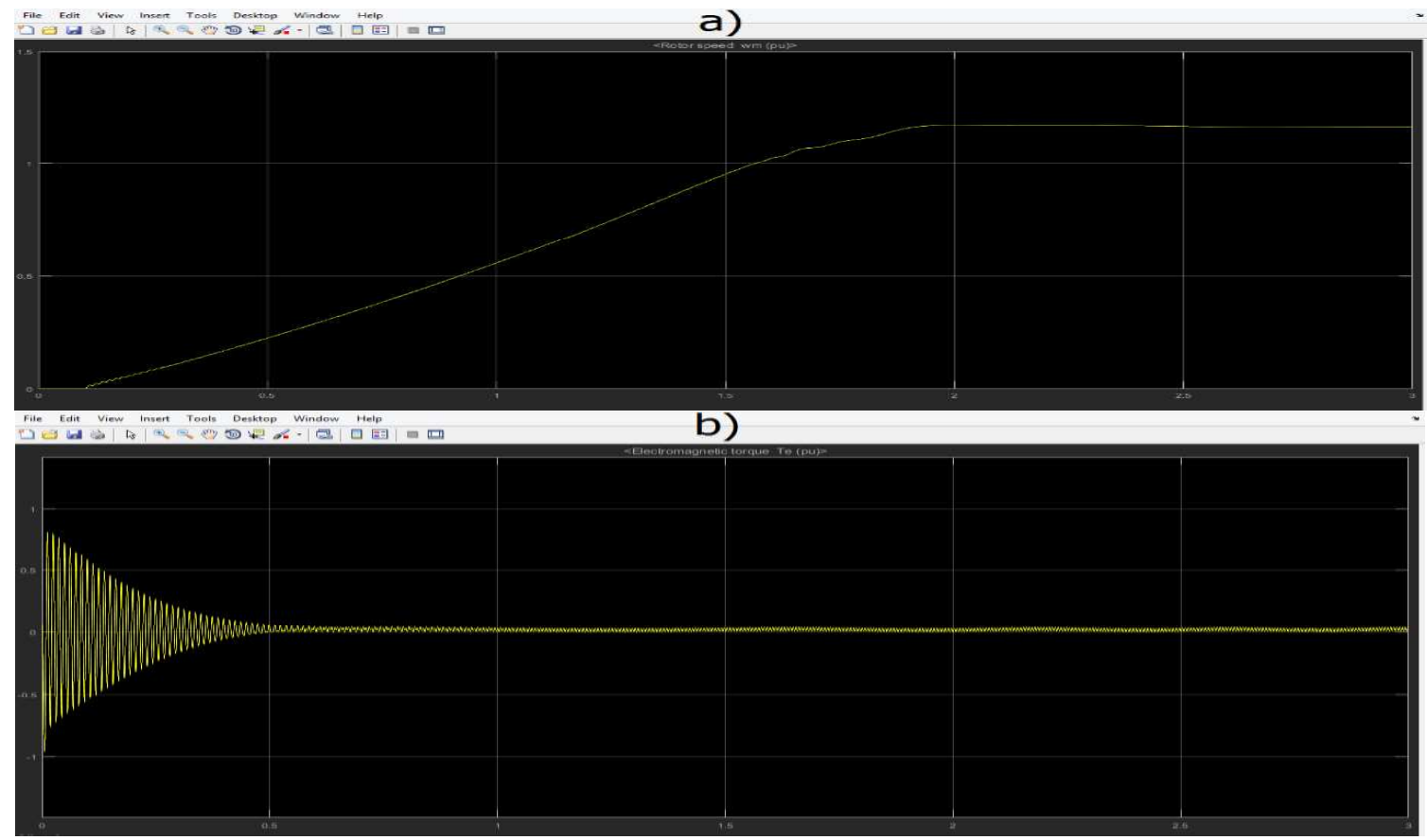

Figure 7. Parameters obtained at $70 \mathrm{~Hz}$ three-phase synchronous motor supply frequency

\subsection{Speed/torque parameters interpretation of three-phase synchronous propulsion motor}

According to theory: the synchronous operates at the synchronous speed:

$$
n_{1}=\frac{60 f_{1}}{p}
$$

where: : $n_{1}$ - synchronous speed, $f_{1}$ - supply voltage frequency, $p$ - pole pair;

regardless of motor shaft load (for a load torque less than the maximum synchronous), so it follows that the speed adjustment can be done by varying the frequency of supply voltage or by changing the number of poles pairs.

This method changes the speed in both directions from the basic speed, corresponding to rated frequency and voltage. Frequency increasing over the nominal speed does not maintain the ratio:

$$
\frac{U}{f}=\text { constant }
$$

where: $U$ - voltage, $f$ - supply frequency;

the effective value of voltage being limited superiorly, otherwise the insulation between stator winding turns is penetrated.

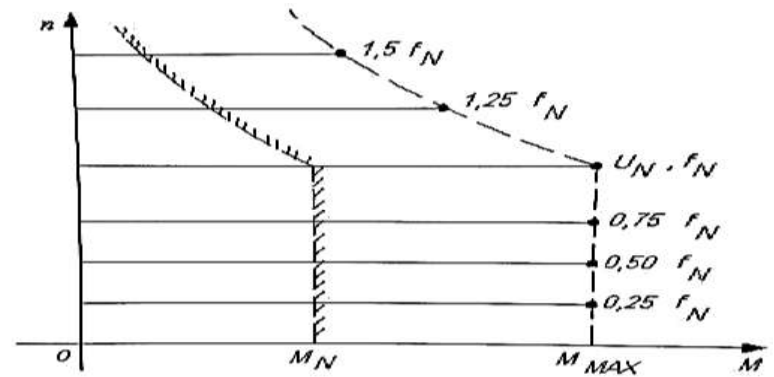

Figure 7. Characteristic curves of torque/speed vs. frequency of the synchronous motor [4] 
For this reason, at frequencies $f>f_{N}$, the maximum torque and torque developed by the motor decreases. [4]

Following the simulation of the first two starts at frequencies $50 \mathrm{~Hz}, 60 \mathrm{~Hz}$ compared to $60 \mathrm{~Hz}$ nominal frequency, mechanical parameters of the motor were represented graphically in figures 5,6. It is found that, after stabilizing the speed (a), the electromagnetic torque (b) is positive and it is kept equal in both cases $(50 \mathrm{~Hz}$ and $60 \mathrm{~Hz})$, for each supply frequency of synchronous motor it corresponds a speed according to formula (22).

In case of the third start of synchronous motor, at $70 \mathrm{~Hz}$ frequency compared to $60 \mathrm{~Hz}$ nominal frequency, mechanical parameters of the motor were represented graphically in figure 7 , it is observed that the value of speed (a) is increased above the nominal one (reached at $60 \mathrm{~Hz}$ ) while the value of electromagnetic torque (b) is decreased; due to exceeding the nominal frequency value.

\section{Conclusions}

All these observations related to the speed/torque ratio are true according to theory. Due to the advantage of synchronous motors, that of keeping constant the motor shaft torque regardless of supply frequency variations, but not higher than nominal frequency, and not exceeding the synchronous torque; synchronous motors becoming more and more widespread in high-power naval electric propulsion.

\section{References}

[1] Espen Skjong, Rune Volden, Egil Rødskar, Marta Molinas, Past, Present and Future Challenges of the Marine Vessel's Electrical Power System, IEEE TRANSACTIONS ON TRANSPORTATION

ELECTRIFICATION 2016,

[2] United Nations Conference on Trade and Development, Review of Maritime Transport 2019, Sales

No. E.19.II.D.20 31 January 2020,

[3] Jan Fredrik Hansen, Alf Ka Êre a Êdnanes, Thor I. Fossen, Mathematical Modelling of Diesel Electric Propulsion Systems for Marine Vessels, 2001, Vol. 7, No. 1, pp. 1-33,

[4] Dobref Vasile Prof. Univ. Dr. Ing., Acționări electrice navale, Ed. PIM Iași, 2017. 